\title{
Numerical Analysis of the Integration of Wind Turbines into the Design of the Built Environment
}

\author{
${ }^{1}$ Hassam Nasarullah Chaudhry, ${ }^{2}$ John Kaiser Calautit and ${ }^{2}$ Ben Richard Hughes \\ ${ }^{I}$ School of Energy, Geoscience, Infrastructure and Society, Heriot-Watt University, Dubai, UAE \\ ${ }^{2}$ School of Civil Engineering, University of Leeds, Leeds, United Kingdom
}

\section{Article history}

Received: 29-11-2014

Revised: 02-12-2014

Accepted: 20-12-2014

Corresponding Author: Hassam Nasarullah Chaudhry, School of Energy, Geoscience, Infrastructure and Society Heriot Watt University, Dubai, UAE Email: H.N.Chaudhry@hw.ac.uk

\begin{abstract}
The effect of wind distribution on the architectural domain of the Bahrain Trade Centre was numerically analysed using Computational Fluid Dynamics (CFD). Using the numerical data, the power generation potential of the building integrated wind turbines was determined in response to the prevailing wind direction. Simulating a reference wind speed of $6 \mathrm{~m} / \mathrm{s}$, the findings from the study quantified an estimate power generation of $6.4 \mathrm{~kW}$ indicating a capacity factor of $2.9 \%$ for the computational model. At the windward side of the building, it was observed that the layers of turbulence intensified in inverse proportion to the height of the building with an average value of $0.45 \mathrm{~J} / \mathrm{kg}$. The air velocity was found to gradually increase in direct proportion to the elevation with the turbine located at higher altitude receiving maximum exposure to incoming wind. This study highlighted the potential of using advanced computational fluid dynamics in order to factor wind into the design of any architectural environment.
\end{abstract}

Keywords: Buildings, Computational Fluid Dynamics, Power Density, Turbulence, Wind Turbine

\section{Introduction}

Building energy is part of a complex system that includes transport and urban planning and has major social consequences as well as climate change impacts. The energy mix is also important in determining carbon dioxide emissions. Buildings worldwide account for a surprisingly high $40 \%$ of global energy consumption and the resulting carbon footprint, significantly exceeding those of all transportation combined. Energy consumption of the Gulf Cooperation Council (GCC) countries is driven largely by residential use, with almost $47 \%$ of the electricity being consumed by the residential sector. Large and attractive opportunities exist to reduce building's energy use at lower costs and higher returns than other sectors. At the same time, substantial investments will be required to achieve this target. These will require the combination of actions called for in this report, including building energy codes, investment subsidies, labelling and reporting mechanisms, increased and trained workforce capacity and evolving energyefficiency designs and technologies. To achieve an energy-efficient world, governments, businesses and individuals must transform the building sector through a multitude of actions, which include increasing energy awareness globally.
Despite the renewable energy generation potential of wind turbines, their integration into high rise building structures has not advanced significantly. Apart from the lack of architectural appeal, the turbulence and wind shadowing effects represent a risk for uptake of the technology in the built environment (Muller et al., 2008). Figure 1 displays examples of existing wind turbines integrated to commercial high rise buildings. In 2007, the Bahrain World Trade Centre introduced the world's first building integrated wind turbines (Fig. 1c). This was the first instance that a commercial development integrated large-scale wind turbines within its design to harness the power of the wind. The three turbines, measuring 29 meters in rotor diameter were supported by bridges spanning between the complex's two towers. Through its positioning and the unique aerodynamic design of the towers, the prevailing on-shore Gulf breeze is intended to be funnelled into the path of the turbines, helping to create power generation efficiency. The anticipated benefits determined that once the system was operational, the wind turbines delivered approximately $11-15 \%$ of the energy needs of the building, or 1,100 to 1,300 megawatt-hours per year (Killa and Smith, 2008).

There are currently two major types of operational wind turbine technologies which can be used for 
building integration. These are classified as the Horizontal Axis Wind Turbines (HAWT) and the Vertical Axis Wind Turbines (VAWT). Horizontal axis wind turbines are the more common type of wind turbines in demand. In these turbines, the focus rotor shaft is pointed parallel to the direction of wind while the blades move perpendicular to that direction, thus providing high overall efficiency. On the other hand, the vertical axis wind turbines orientate on vertical axis where the focus rotor shaft is aligned vertically. A twodimensional 'not-to-scale' design modeling based on the two wind turbine technologies is shown in Fig. 2. The schematic provides the essential information on the individual situation of the major components in the wind turbine structure (Killa and Smith, 2008).

Theoretically, the air velocity incrimination is directly proportional to increasing elevation, as it is unaffected by the urban environment and surrounding topography. Thus, installing wind turbines on top of buildings allows for taking advantage of this height efficiently (Hughes et al., 2011). However, in many cases, the building geometry and its aerodynamic features can further assist in enhancing wind turbine performance by inducing a higher volume of air than the macro-climate (Hughes and Chaudhry, 2011).
Numerical analyses involving Computational Fluid Dynamics (CFD) are often carried out for evaluating building design and energy performances. In the past few years, CFD has been playing an increasingly important role in the design of buildings. The information provided by CFD assists in investigating the impact of building technologies, quantifying indoor environment quality and in integrating renewable energy systems. In this study, the CFD modeling approach is used out in order to determine the influence of building morphology on the efficiency of building-integrated wind turbines.

\section{Previous Related Works}

Work related to implementation of renewable energy as power sources in buildings, in particular wind energy is rapidly increasing. Following is a concise assessment of previous work related to this investigation.

Chong et al. (2013) conducted a study on the design of a wind turbine generator for the purpose of energy consumption in buildings. Two VAWTs in cross-wind orientation were integrated with an enclosure were installed above a cooling tower in order to harness the discharged wind for electricity generation. The tests were conducted with and without the VAWTs on the performance of the system.

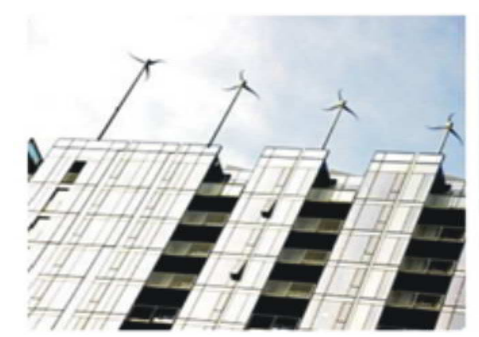

(a)

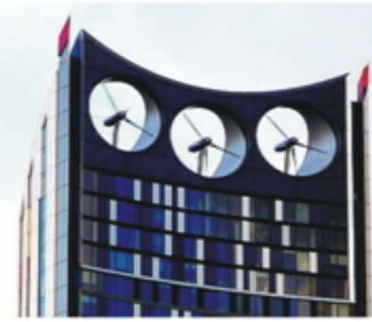

(b)

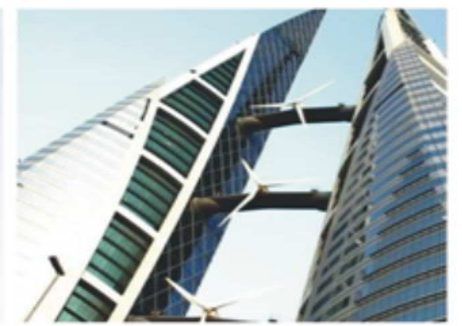

(c)

Fig. 1. (a) Wind turbines on the roof of twelve west building; (b) the Strata tower with three building-integrated wind turbines; (c) Bahrain World Trade Centre

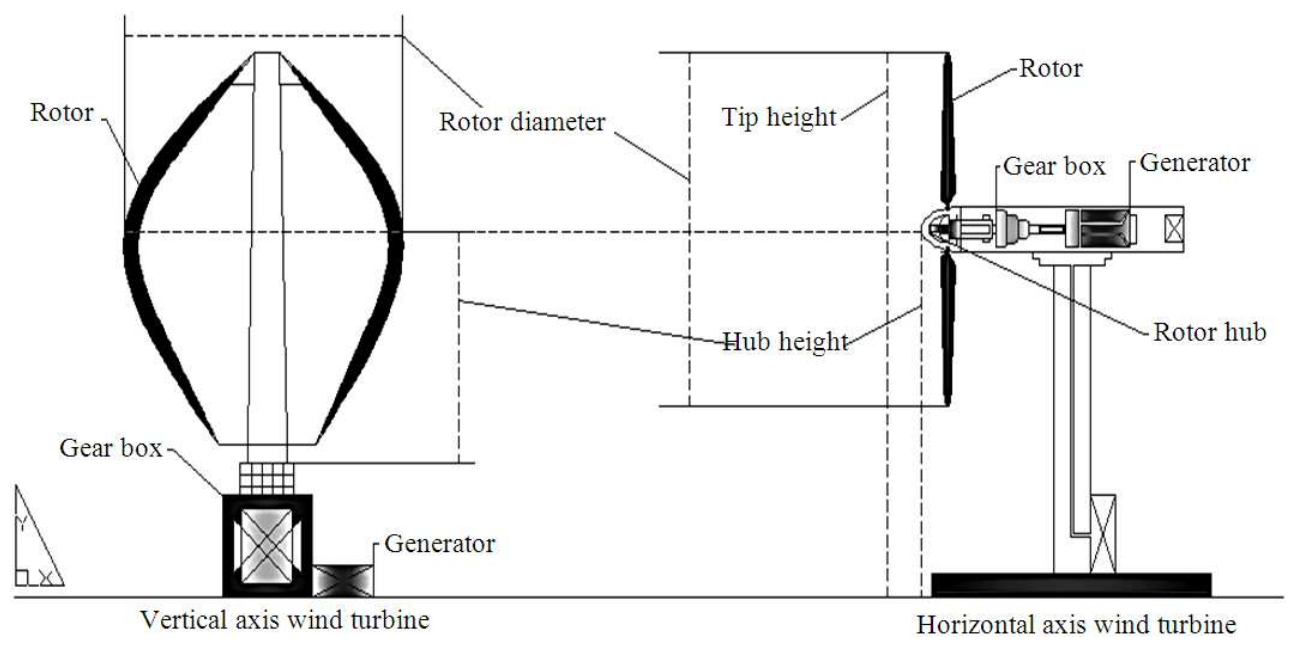

Fig. 2. Structural comparison between the horizontal axis wind turbines and vertical axis wind turbines (Chaudhry and Hughes, 2011) 
From the laboratory testing, it was observed that installing VAWTs at a correct position above the exhaust air system did not indicate any significant negative impacts on the performance of the cooling tower model. The performance of the cooling tower model was improved by the increment of intake air speed and the reduction off the motor power consumption. The rotational speed of the VAWTs were very high $(>400 \mathrm{rpm})$ while the tip speed ratios were in the range of $1.28-1.29$, making it preferable for electricity generation.

Sharpe and Proven (2010) carried out detailed work on the concept and early development of a building integrated wind turbine in Scotland. The Crossflex proposal used in this investigation is based on the Darrieus turbines approach, consisting of two or more flexible aero foil blades attached to both the top and bottom of a vertical rotating shaft. The blade design incorporated low solidity and low mass materials for its construction. Although the development of this technology is still in its early stage, the study has outlined the remaining tasks of its work. The subsequent stages will involve supplementary computer modeling using CFD analysis to model airflow over the cowling to establish the nature of augmentation and flow stability that may occur and to optimise the design in respect of these.

Lu and Sun (2014) presented an integrated method of both macro (weather data and domain topography) and micro aspect (CFD) analysis in order to design wind turbines around numerous high-rise buildings with predominant wind in Hong Kong. Long-term wind data were compared at dense urban island and small island stations. The mean wind speeds for the urban locations were estimated at $2.93 \mathrm{~m} / \mathrm{s}$ at $25 \mathrm{~m}$ above ground level. The study's findings determined that the wind power density at $4 \mathrm{~m}$ above the building roof was enhanced numerously by $1.3-5.4$ times with $5-7 \mathrm{~m} / \mathrm{s}$ inlet velocity.

Mithraratne (2009) investigated the performance of wind turbines mounted on roof-tops, used for microgeneration in municipal houses in New Zealand. The research focused on energy consumption over a lifetime of the wind turbine with respect to the energy generation and Green House Gas (GHG) emissions at various circumstances in the life cycle. The work concluded that the feasibility level of roof-top wind turbines is generally poor as compared to large scale wind turbines for micro-generation.

Li et al. (2013) investigated the wind loads on the Pearl River Tower building in China to determine the power generation potential of wind turbines using wind tunnel testing. The Pearl River Tower, located in Guangzhou has 71 stories and rises about $310 \mathrm{~m}$ from the ground, which features four open holes (tunnels) equipped with four wind turbines at mechanical floors on two height levels. The objective of this study was to evaluate the wind speed amplifications in the tunnels for wind-power generation through the installation of wind turbines and to gain a better understanding of the wind effects on such a high-rise building with open holes. The findings from the analyses indicated that the bell-mouthed shape of the wind tunnels with contracted inner sections were useful in increasing the wind velocities at the location of the turbines. In addition, the work revealed that the presence of surrounding buildings influences wind speed amplifications and wind loads on the building structure.

In this study, the effect of wind distribution on the architectural domain of the Bahrain Trade Centre is numerically analysed using CFD. Individual parameters including air velocity distribution, pressure profiles and turbulence kinetic energy were computationally investigated to illustrate the variations in relation to increasing altitude. The power generation potential of the building integrated wind turbines were then determined using the study's findings.

\section{Computational Methodology}

The computational domain comprised of the building geometry, which was designed according to the actual specifications of the high-rise tower and the specific wind turbines. The two 50 storey sail shaped towers are reported to measure to a height of $240 \mathrm{~m}$ and support three horizontal-axis wind turbines incorporating a rotor diameter of $29 \mathrm{~m}$ (Muller et al., 2008).

The three-dimensional Reynolds-Averaged NavierStokes (RANS) equations along with the momentum and continuity equations were solved using the commercial CFD code for the velocity and pressure field simulations. The model employs the control-volume technique and the Semi-Implicit Method for Pressure-Linked Equations (SIMPLE) velocity-pressure coupling algorithm with the second order upwind discretisation. The standard k-e transport model which is frequently used for incompressible flows was used to define the turbulence kinetic energy and flow dissipation rate within the model (Launder and Spalding, 1972). The use of the standard k-e transport model on building configurations has been found in previous works of (Calautit et al., 2013a; 2013b; Hughes et al., 2012)]. The turbulence kinetic energy, $k$ and its rate of dissipation, $e$, are obtained from the following transport equations formulated in Equation 1 and 2:

$$
\begin{aligned}
& \frac{\partial}{\partial t}(\rho k)+\frac{\partial}{\partial x_{i}}\left(\rho k u_{i}\right)=\frac{\partial}{\partial x_{j}}\left[\left(\mu+\frac{\mu_{t}}{\sigma k}\right) \frac{\partial k}{\partial x_{j}}\right] \\
& +G_{k}+G_{b}-\rho \in-Y_{M}+S_{k} \\
& \frac{\partial}{\partial t}(\rho e)+\frac{\partial}{\partial x_{i}}\left(\rho e u_{i}\right)=\frac{\partial}{\partial x_{j}}\left[\left(\begin{array}{c}
\mu+ \\
\sigma_{e}
\end{array}\right) \begin{array}{l}
\partial k \\
\partial x_{j}
\end{array}\right] \\
& +C_{1 e}^{e}{ }_{k}^{e}\left(G_{k}+C_{3 e} G_{b}\right)-C_{2 \epsilon} \rho_{k}^{e^{2}}+S_{e}
\end{aligned}
$$




$$
\begin{aligned}
& \text { Where: } \\
& G_{k} \quad=\text { Represents the generation of }
\end{aligned}
$$

\section{Mesh Generation}

Mesh generation is one of the most important processes in CFD simulation. The quality of the mesh plays an important role on the accuracy of results and the stability of the solution. For the investigated computational domain, patch independent CFD tetrahedron meshing technique was applied on the geometry wherein the boundary conditions were applied on the edges and faces. The patch independent mesh algorithm for tetrahedron elements is based on the subsequent spatial subdivision algorithm which ensures refinement of the mesh where essential, but retains larger elements where feasible, therefore allowing faster computing times. The meshed model comprised of $2,013,428$ nodes and 10,849,999 elements as displayed in Fig. 2. The minimum face angle was $5.67^{\circ} \mathrm{C}$ while the maximum edge length and element volume ratios were 9.9 and 44.6. Figure 3 and. 4 displays the schematic of the geometry along with the meshed model.

\section{Grid Independency}

In order to verify the accuracy of the numerical models, a grid independency test was carried out to determine the variation in results over increasing mesh sizes. Basic concepts associated with mesh refinement deals with the refinement and evaluation of elements where the posterior error indicator is larger than the preset criterion, while mesh enrichment considers running higher order polynomials till the solution is expected to improve with a fixed mesh (Chung, 2002). Grid verification was carried out using mesh refinements (h-method) in order to optimise the distribution of mesh size $\mathrm{h}$ over a finite element.

The area-weighted average value of the static pressure on the three wind turbines located on the building façade was taken as the error indicator, as the grid was refined from $1,519,000$ to $10,849,999$ elements with the average pressure value being $4.36 \mathrm{~Pa}$. The grid was evaluated and refined until the posterior estimate error became insignificant between the number of elements and the posterior error indicator. The discretisation error was found to be the lowest at over ten million elements for both indicated variables and the mesh was thus selected to achieve a balance between accuracy and computational time. The $y+$ values at the wall varied between 5 and 61 . Fig. 5 displays the wall $y+$ values and variation in discretisation error at increasing number of meshed elements.

\section{Boundary Conditions}

The applied boundary conditions (Table 1) comprised of a reference velocity $\left(u_{r e f}\right)$ of $6 \mathrm{~m} / \mathrm{s}$ at a height of $300 \mathrm{~m}$ $\left(z_{r e f}\right)$ approaching directly perpendicular to the building façade (Kubik et al., 2011). The geometry was modeled as a solid zone while the enclosure was modeled as a fluid zone for the analyses. The boundary conditions were kept identical throughout the numerical investigation for all analysed models.

\section{Wind Energy Potential in Bahrain}

Figure 6 displays the wind days per month and wind direction distribution in Bahrain (WWSBA, 2014). The predominant wind direction was observed to be from the North West. Evidently, the building structure was oriented in the direction of the dominant prevailing wind in order to allow the turbines to operate at maximum efficiency.

In order to estimate how much energy a specific turbine will be expected to produce at a given location, the wind resource at that location must be identified. A wind turbine works by extracting kinetic energy out of the wind and converting it to mechanical and then electrical energy. The power that is available in the wind to be converted to electrical energy is defined in Equation 3:

$$
P_{\text {wind }}=\frac{1}{2} \rho A U^{3}
$$

Where:

$$
\begin{aligned}
& P_{\text {wind }}=\text { Power available in the wind } \\
& \rho=\text { Density of air } \\
& A \quad=\text { Swept area of the turbine } \\
& U \quad=\text { Wind speed approaching the wind turbine }
\end{aligned}
$$

Table 1 . Boundary conditions

\begin{tabular}{ll}
\hline Parameter & Type \\
\hline Geometry & Solid zone \\
Enclosure & Fluid zone \\
Operating Pressure & Atmospheric \\
Viscous model & k-epsilon (2 Equation) \\
Near-wall treatment & Standard wall functions \\
Velocity formulation & Absolute \\
Solver type & Pressure-based \\
Time & Steady \\
Gravity & $-9.81 \mathrm{~m} / \mathrm{s}^{2}$ \\
\hline
\end{tabular}




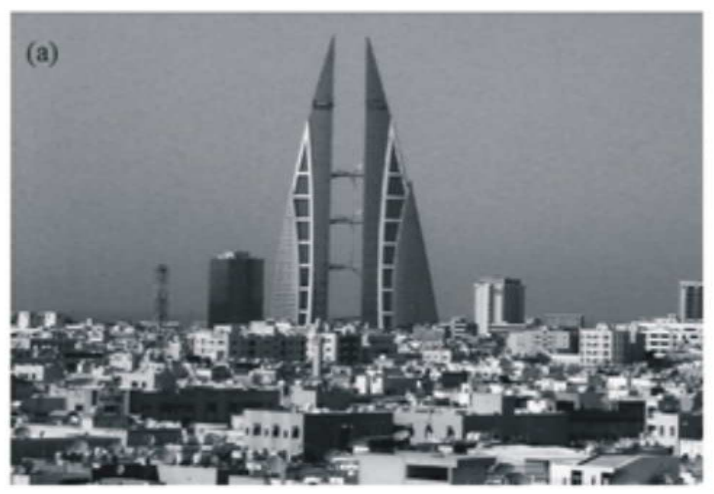

(a)

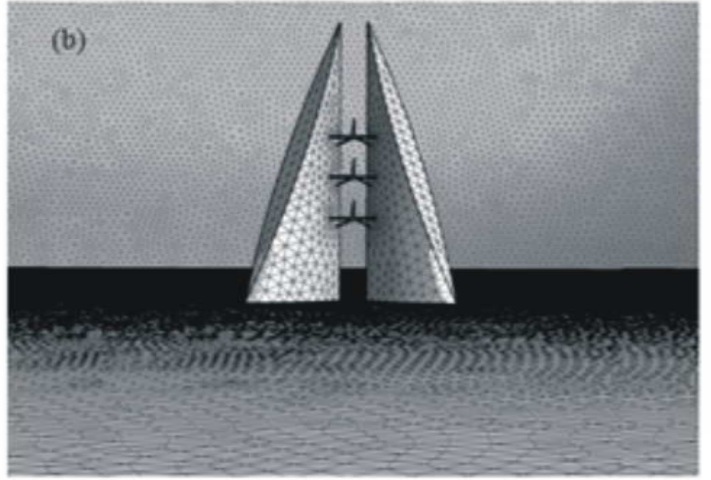

(b)

Fig. 3. (a) Actual building configuration (b) meshed model

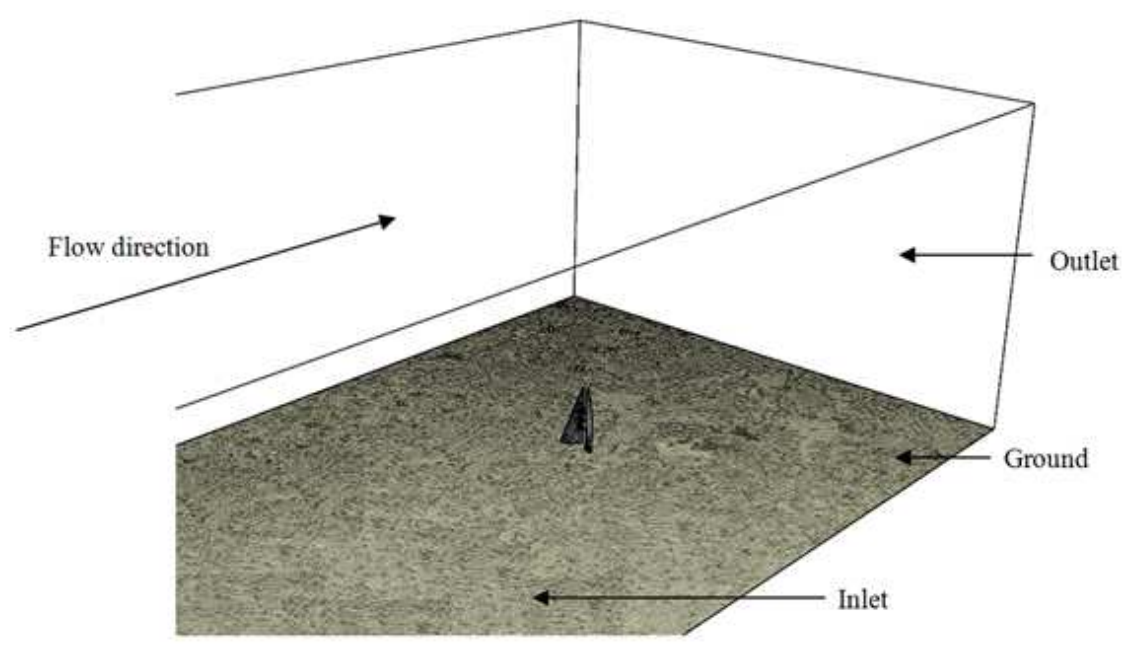

Fig. 4. Representation of the flow domain
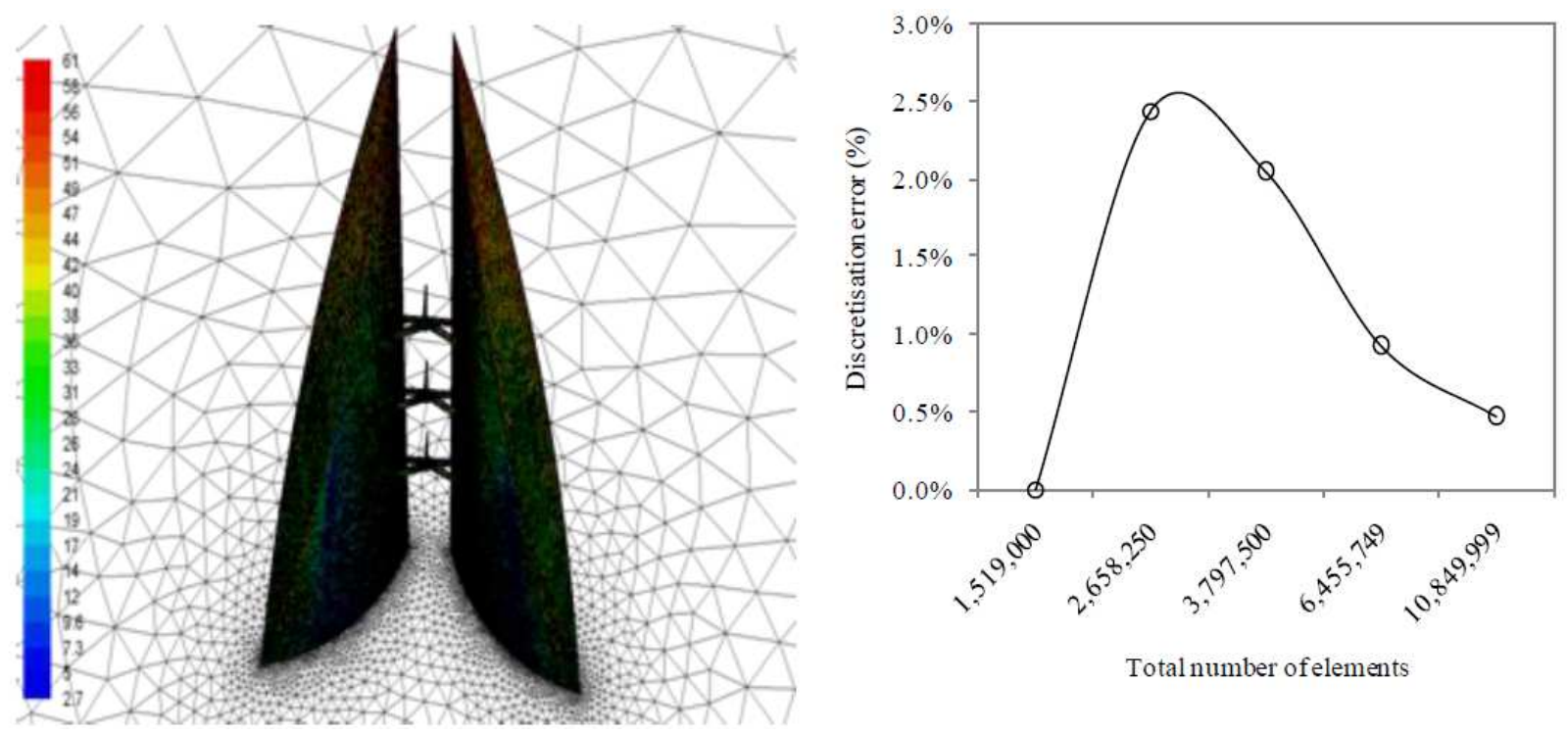

Fig. 5. Variation in discretisation error at increasing number of elements 

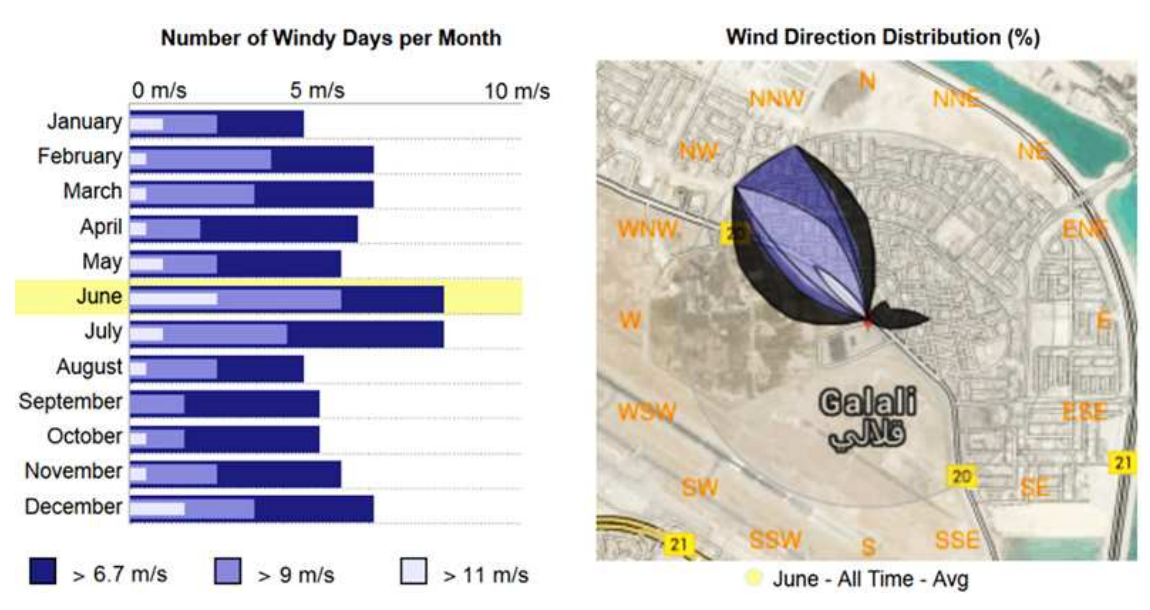

Fig. 6. (a) Wind days per month and (b) wind direction distribution in Bahrain (WWSBA, 2014)

Large-scale integration of wind turbines into buildings requires extensive research and development for it to operate at high efficiencies in order to balance out the high cost of installation. The specification of the wind turbines used in this study was mapped on the ones installed on the Bahrain Trade Centre. The fixed horizontal axis wind turbine comprised of a conventional nacelle design containing an enclosure with the gearbox, cooling system and the associated control system. The nominal electrical power rating of the turbine was 225 $\mathrm{kW}$ with the rotor diameter measuring $29 \mathrm{~m}$. The rotor speed at full load was $38 \mathrm{rpm}$. The cut-in wind speed for the wind turbine operation was $4 \mathrm{~m} / \mathrm{s}$ while the cut-out speed was $20 \mathrm{~m} / \mathrm{s}$ (Muller et al., 2008).

Since the potential power production is proportional to the wind speed cubed, the annual mean wind power density cannot be defined by strictly using the mean annual wind speed. However, some knowledge of the wind distribution must be known to estimate the power density. The power density $\left(P_{\text {density }}\right)$ can be used as a function of the power divided by the area and the expression is displayed in Equation 4:

$$
P_{\text {density }}=\frac{1}{2} \rho U^{3}
$$

Using the computational domain, a representation of velocity boundary layer profile and turbulence intensity $(I)$ at the windward side of the building is shown in Fig. 7 wherein the wind speed is taken from the direction of the sea. The thickness of boundary layer of the atmosphere varies with wind speed, turbulence level and the type of surface. The power law is an empirical equation expressed in Equation 5. For neutral stability conditions, $\alpha$ is approximately $1 / 7$, or 0.143 , regarded as a reasonable but conservative estimate (Kubik et al., 2011):

$$
u=u_{\text {ref }}\left(\frac{z}{z_{\text {ref }}}\right)^{\alpha}
$$

Where:

$\mathrm{u}=$ Speed at a particular point

$u_{\text {ref }}=$ Reference speed

$\mathrm{z}=$ Height at a particular point

$z_{\text {ref }}=$ Reference height

\section{Results and Discussion}

\section{Pressure, Velocity and Turbulence Profiles}

Using the building model, Fig. 8 displays the contour levels for static pressure as the air comes in contact with the building. A positive airside pressure was created as the air stream came in direct contact with the building façade. This was due to the force being directly perpendicular to the area of interaction. As a result, a negative pressure was created on the opposite end at the immediate downstream of the building where the air velocity increased due to the streamlined body of the structure. The maximum positive pressure was estimated at $20 \mathrm{~Pa}$ while the maximum negative pressure was observed to be $-14 \mathrm{~Pa}$. The analysis showed that a total pressure differential of $34 \mathrm{~Pa}$ was created for the entire geometry.

Figure 9 and 10 displays the contour levels of velocity and turbulence kinetic energy, upstream and downstream of the building model. The findings displayed that the air velocity gradually increased to $7.1 \mathrm{~m} / \mathrm{s}$ from a reference velocity of $6 \mathrm{~m} / \mathrm{s}$. At the windward side of the building, it was observed that the layers of turbulence intensified in inverse proportion to the height of the building with an average value of $0.45 \mathrm{~J} / \mathrm{kg}$. The turbulence kinetic energy was however found to increase (maximum value of $1.35 \mathrm{~J} / \mathrm{kg}$ ) at the leeward side of the building as the wind came in contact and sheared away towards the sides of the structure. 

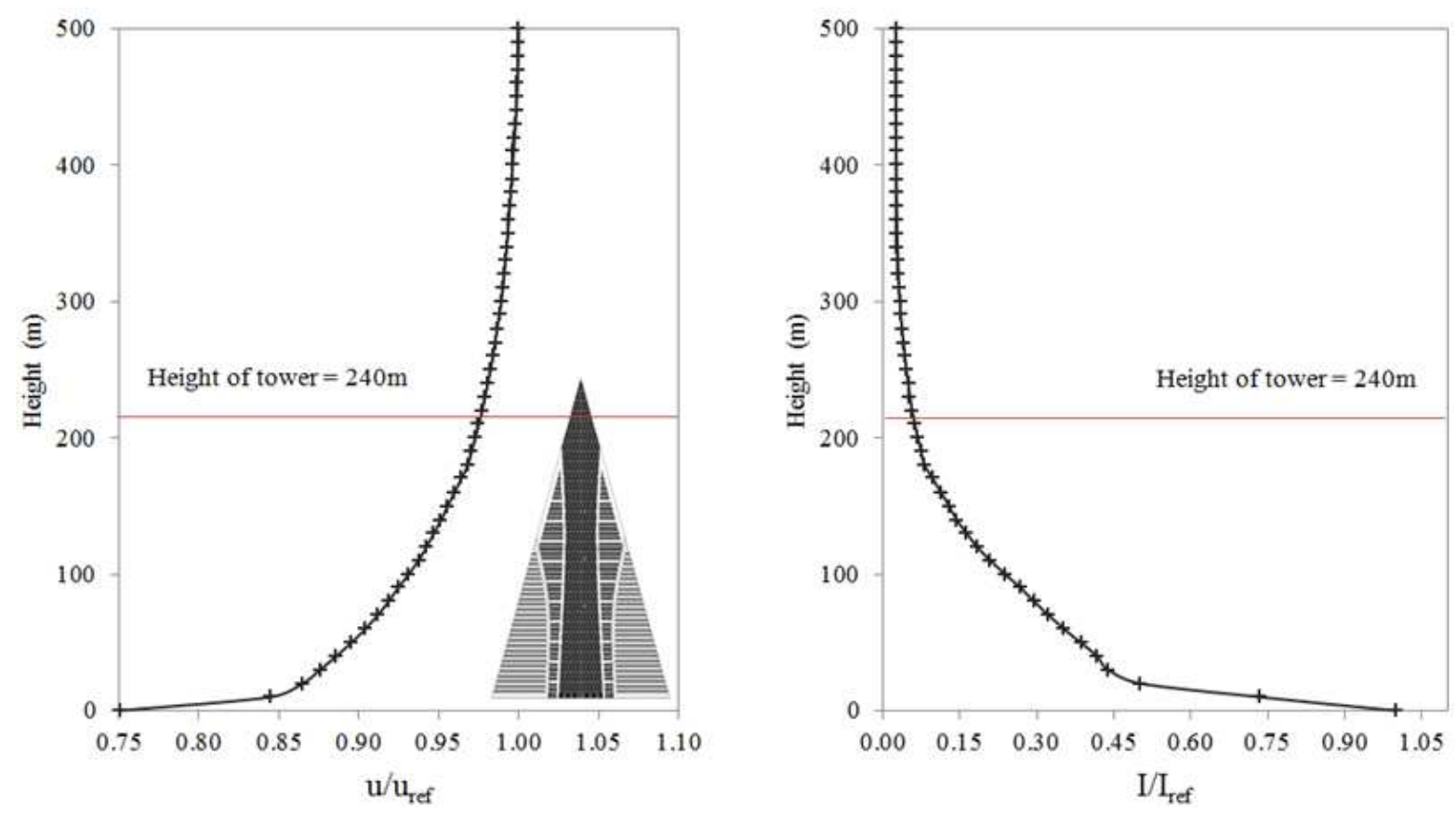

Fig.7. Representation of the boundary layer profile and turbulence intensity

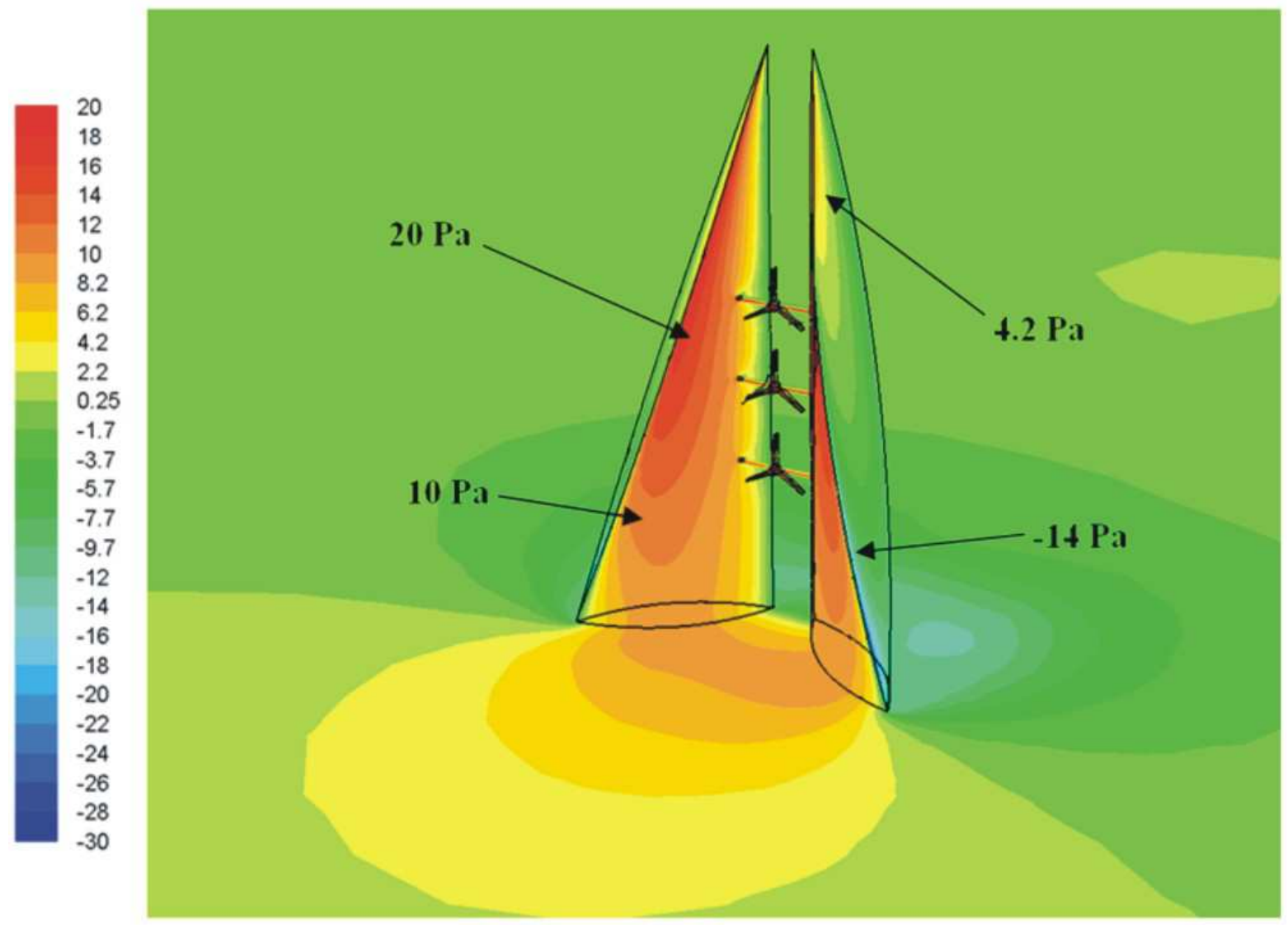

Fig. 8 Contour levels of static pressure on the surface of the building and ground 
Hassam Nasarullah Chaudhry et al. / American Journal of Engineering and Applied Sciences 2014, 7 (4): 363.373 DOI: 10.3844/ajeassp.2014.363.373

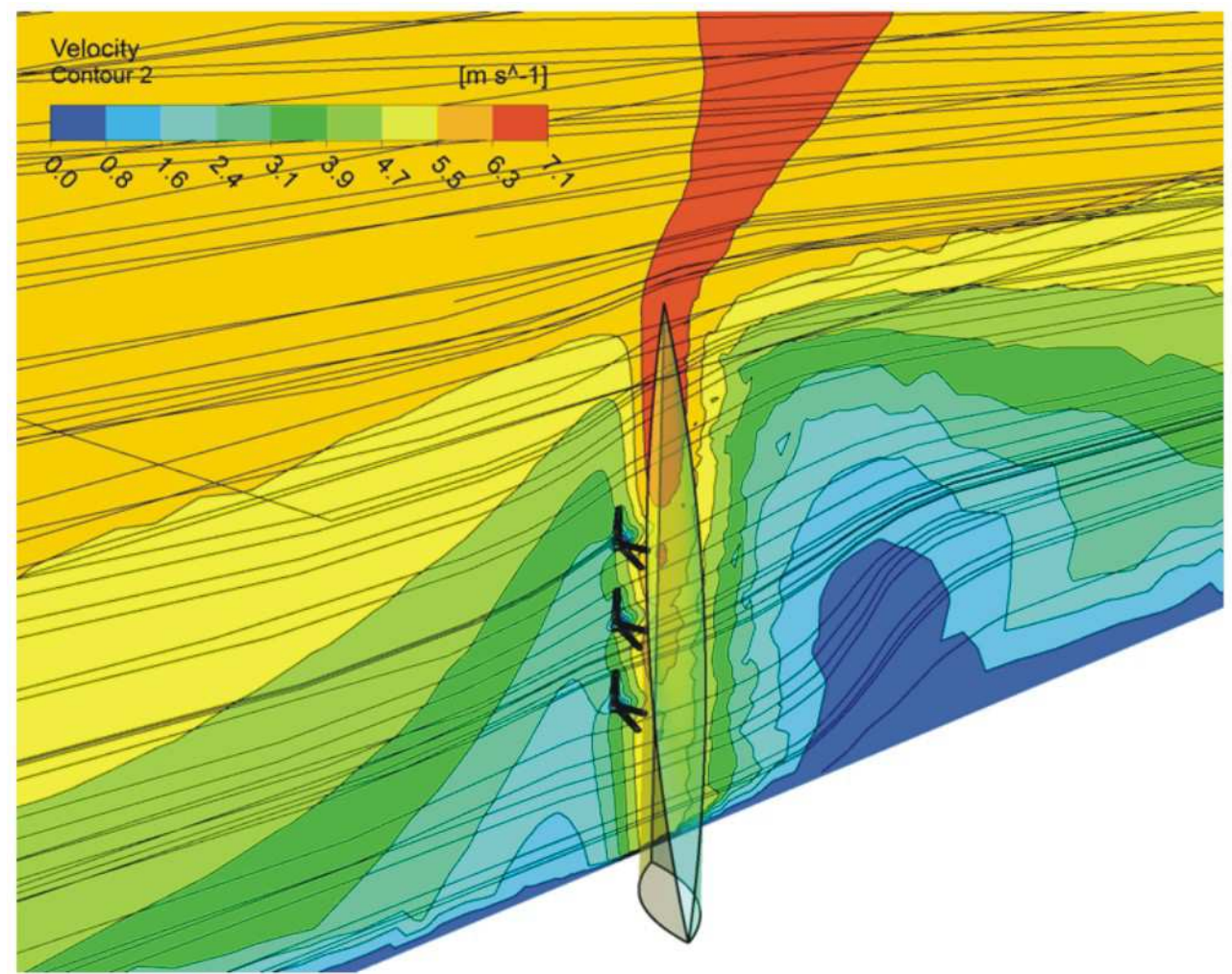

Fig. 9. Streamlines and contour levels of velocity magnitude formation upstream and downstream of the building

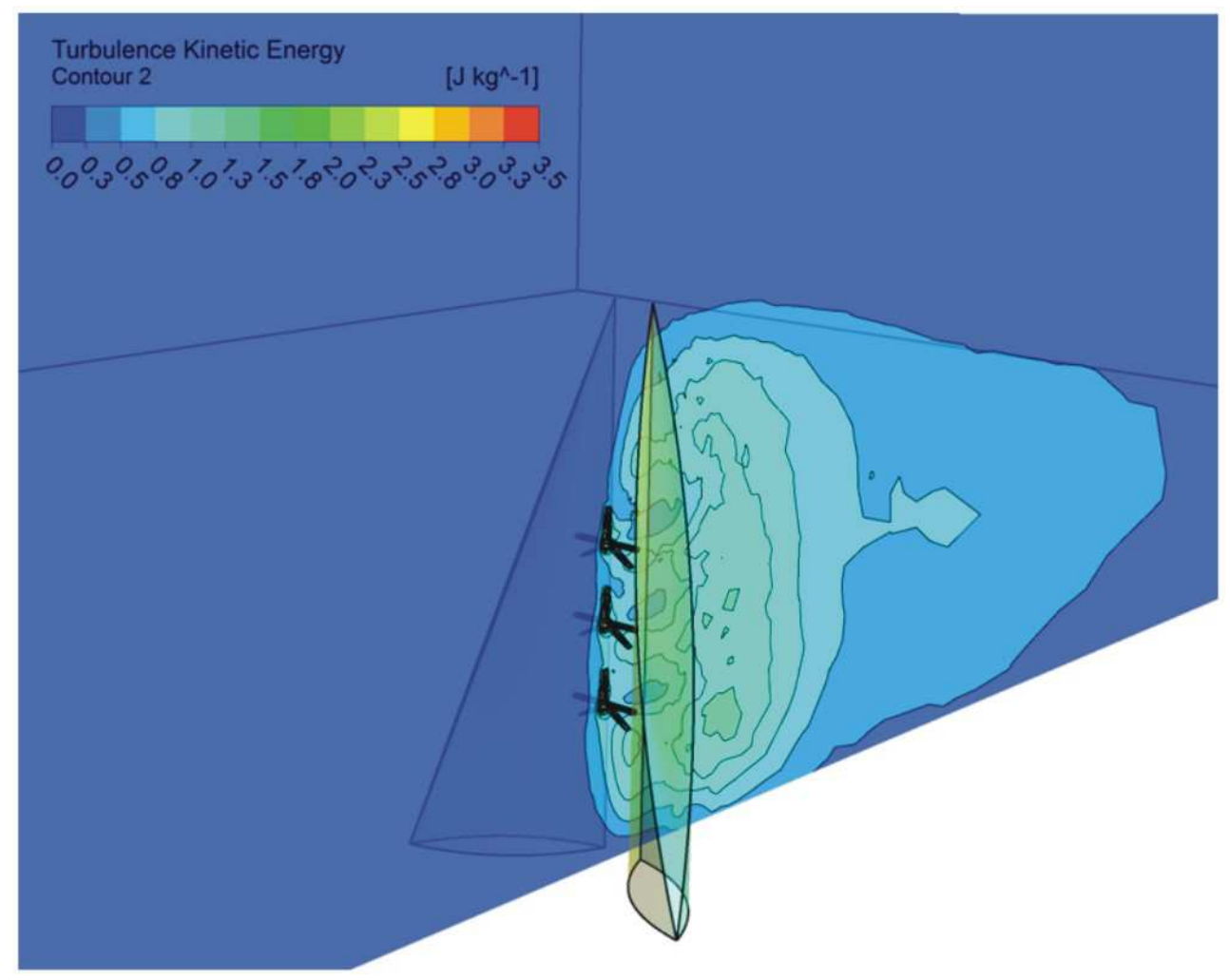

Fig. 10. Contour levels of turbulence kinetic energy upstream and downstream of the building 

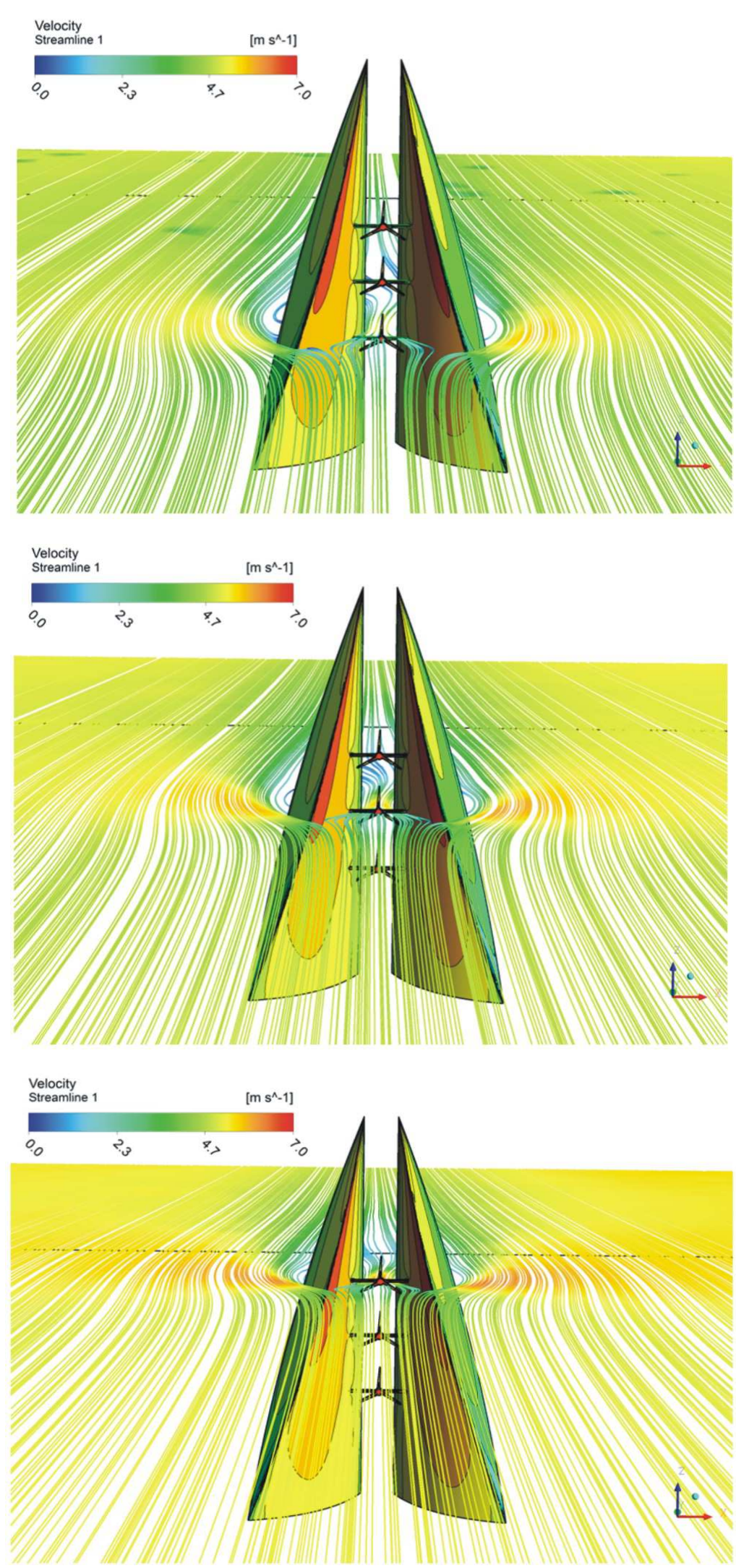

Fig. 11. Velocity streamlines formation around the three levels (low-altitude, mid-altitude and high-altitude) of wind turbines 


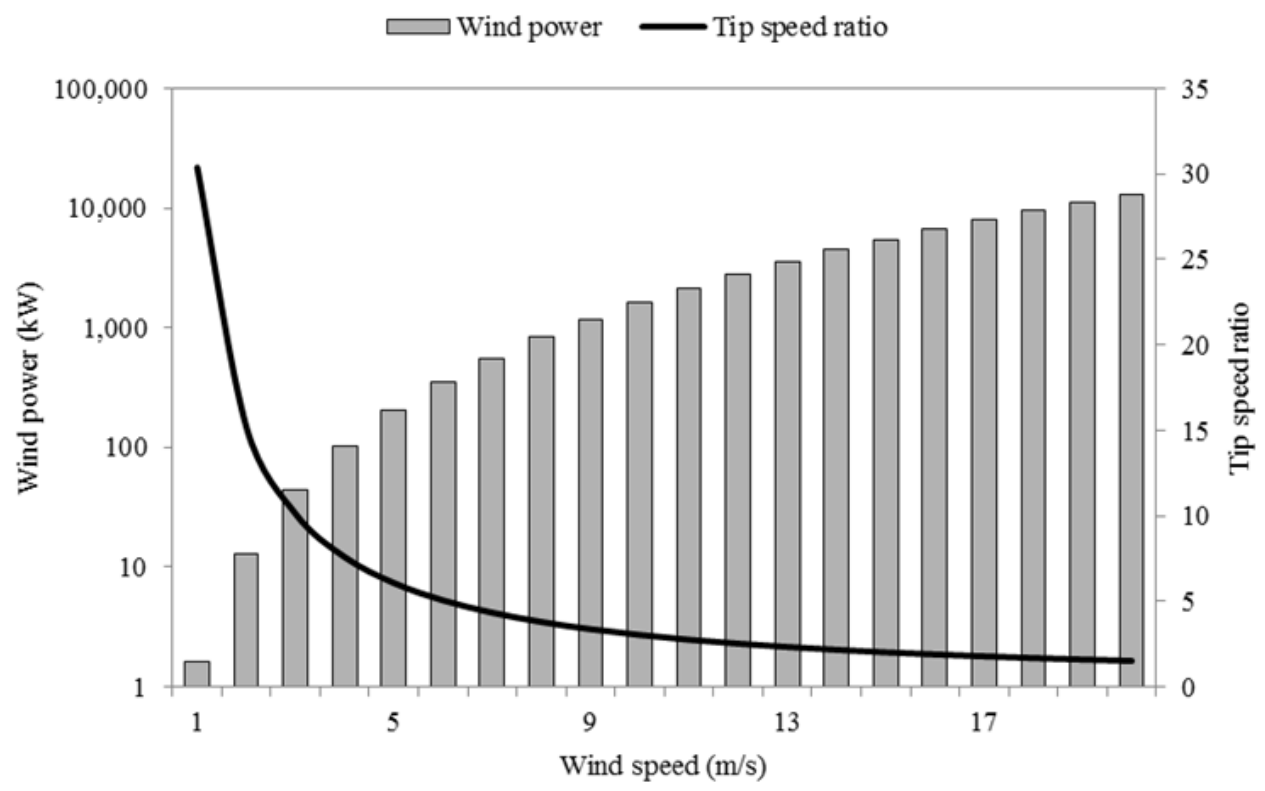

Fig. 12. Analytical relationship between wind power and tip speed ratio at increasing wind speeds

Table 2. Estimated power density and capacity factor

\begin{tabular}{lllll}
\hline Turbine & $\begin{array}{l}\text { Velocity } \\
(\mathrm{m} / \mathrm{s})\end{array}$ & $\begin{array}{l}\text { Estimated } \\
\text { power }(\mathrm{W})\end{array}$ & $\begin{array}{l}\text { Power density } \\
(\mathrm{W} / \mathrm{m} 2)\end{array}$ & $\begin{array}{l}\text { Capacity } \\
\text { factor }(\%)\end{array}$ \\
\hline 1 & 2.6 & - & - & - \\
2 & 3.3 & - & - & - \\
3 & 4.1 & 6,430 & 43.1 & $2.9 \%$ \\
\hline
\end{tabular}

Figure 11 displays the formation of velocity streamlines around the three levels (low-altitude, midaltitude and high-altitude) of wind turbines. As observed, the air velocity on approach increases by $17 \%$ when it comes in contact with the wind turbine located at the highest altitude in relation to the wind turbine located at the lowest level.

\section{Power Density and Turbine Capacity Factor}

Following the numerical investigation, an estimation of the wind power characteristics was calculated theoretically. Using the rotor diameter of $29 \mathrm{~m}$ for the wind turbine used in the Bahrain Trade Centre, an analytical comparison between power in the wind and the tip speed ratio is illustrated in Fig. 12. Wind turbines are designed to operate at their optimum tip speed ratio in order to extract as much power possible from the air stream. For a grid connected wind turbine with three rotor blades, the optimum tip speed ratio is recommended between 6 and 8 (Cetin et al., 2005). While a linear increase in wind power was obtained with increasing wind speeds, the recommended tip speed ratio values were found to be at 4 and $5 \mathrm{~m} / \mathrm{s}$ respectively.

Using the wind speeds obtained from the CFD models, the conservative figures of estimated power generation capability of wind turbines for all analysed cases is displayed in Table 2. Three wind turbines were used on the buildings which were categorised as Turbine 1 (low-altitude), Turbine 2 (mid-altitude) and Turbine 3 (high-altitude). Using the computational model, the study quantified an estimate power generation of $6.4 \mathrm{~kW}$ indicating a capacity factor of $2.9 \%$.

\section{Conclusion}

In this study, the feasibility of implementing building-integrated wind turbines was determined by investigating the effect of structural morphology on the extraction of prevailing inlet wind. The power generation capacity of wind turbines was determined using the specifications of the Bahrain Trade Centre. The threedimensional Reynolds-averaged Navier-Stokes (RANS) equations along with the momentum and continuity equations were solved using the commercial CFD code for velocity and pressure field simulations. Using a reference wind speed of $6 \mathrm{~m} / \mathrm{s}$, the findings revealed an increase of $15.4 \%$ in velocity obtained at the top of the tower. The study quantified an estimate power generation of $6.4 \mathrm{~kW}$ indicating a capacity factor of $2.9 \%$ for the building model. This study highlighted the potential of using advanced computational techniques in order to factor the effect of wind distribution into the design of any architectural environment. 


\section{Author's Contributions}

The authors performed the CFD modelling, simulation and analysis of the integration of the wind turbine into the building. Following the CFD investigation, the team estimated the power density and capacity factor of each turbine.

\section{References}

Calautit, J.K., B.R. Hughes and S.A. Ghani, 2013a. Numerical investigation of the integration of heat transfer devices into wind towers. Chem. Eng. Trans., 34: 43-48. DOI: 10.3303/CET1334008

Calautit, J.K., B.R. Hughes and S.A. Ghani, 2013b. A Numerical investigation into the feasibility of integrating green building technologies into row houses in the Middle East. Architectural Sci. Rev., 56: 279-296. DOI: 10.1080/00038628.2012.686433

Cetin, N.S., M.A., Yurdusev, R. Ata and A. Ozdemir, 2005. Assessment of optimum tip speed ratio of wind turbines. Math. Comput. Applic., 10: 147-154.

Chaudhry, H.N. and B.R. Hughes, 2011. Computational analysis of dynamic architecture. J. Power Energy, 225: 85-95. DOI: 10.1177/09576509JPE1056

Chong, W.T., S.Y. Yip, A. Fazlizan, S.C. Poh and W.P. Hew et al., 2013. Design of an exhaust air energy recovery wind turbine generator for energy conservation in commercial buildings. Renewable Energy, 67: 252-256. DOI: 10.1016/j.renene.2013.11.028

Chung, T.J., 2002. Computational Fluid Dynamics. 1st Edn., Cambridge University Press.

Hughes, B.R. and H.N. Chaudry, 2011. Power generation potential of dynamic architecture. World Acad. Sci., Eng. Technol., 5: 01-24.

Hughes, B.R., J.K. Calautit and S.A. Ghani, 2012. The development of commercial wind towers for natural ventilation: A review. Applied Energy, 92: 606-627. DOI: 10.1016/j.apenergy.2011.11.066

Hughes, B.R., H.N. Chaudhry and S.A. Ghani 2011. A review of sustainable cooling technologies in buildings. Renewable Sustainable Energy Rev., 15: 3112-3120. DOI: 10.1016/j.rser.2011.03.032
Killa, S. and R.F. Smith, 2008. Harnessing energy in tall buildings: Bahrain world trade center and beyond. Proceedings of the Council of Tall Buildings and Urban Habitat (CTBUH) 8th World Congress, Mar. 3-5, Dubai, UAE.

Kubik, M.L., P.J. Coker and C. Hunt, 2011. Using meteorological wind data to estimate turbine generation output: A sensitivity analysis. Proceedings of the World Renewable Energy Congress, May 8-13, Linkoping, Sweden, pp: 4074-4081.

Launder, B. and D.B. Spalding, 1972. Lectures in Mathematical Models of Turbulence. 1st Edn., Academic Press, London, England, ISBN-10: 0124380506, pp: 169.

Li, Q.S., F.B. Chen, Y.G. Li and Y.Y. Lee, 2013. Implementing wind turbines in a tall building for power generation: A study of wind loads and wind speed amplifications. J. Wind Eng. Indus. Aerodynam., 116: 70-82. DOI: 10.1016/j.jweia.2013.03.004

Lu, L. and K. Sun, 2014. Wind power evaluation and utilization over a reference high-rise building in urban area. Energy Build., 68: 339-350. DOI: 10.1016/j.enbuild.2013.09.029

Mithraratne, N., 2009. Roof-top wind turbines for microgeneration in urban houses in New Zealand. Energy Build., 41: 1013-1018. DOI: 10.1016/j.enbuild.2009.05.003

Muller, G., F. Jentsch Mark and E. Stoddart, 2008. Vertical axis resistance type wind turbines for use in buildings. Renewable Energy, 34: 1407-1412. DOI: 10.1016/j.renene.2008.10.008

Sharpe, T. and G. Proven, 2010. Crossflex: Concept and early development of a true building integrated wind turbine. Energy Build., 42: 2365-2375. DOI: 10.1016/j.enbuild.2010.07.032

WWSBA, 2014. Wind and weather statistics Bahrain Airport. Windfinder. 